\title{
As redes coordenadas pelo Observatório Social no Brasil: promoção de capacitação e suporte técnico
}

\author{
DOI: http://dx.doi.org/10.20435/inter.v20i3.2731
}

Tendo a função objetiva de ser um sistema propulsor de controle social voltado ao aprimoramento da gestão pública, o Observatório Social no Brasil conta com mais de 3.500 voluntários que se preocupam pelo Brasil afora, primeiramente com a justiça social. Sendo apartidária, cidadã e comprometida com os problemas sociais, as redes do Observatório Social assumem uma atitude ética, proativa, técnica, com ações preventivas com o olhar na cidadania fiscal e, principalmente, no dinheiro público bem empregado.

Outra importante função volta-se à disseminação de ferramentas educativas de cunho fiscal para inserir micro e pequenas empresas no rol de fornecedores de prefeituras municipais. O controle social tem a função de ser exercido, conforme as ponderações de Abrucio e Loureiro (2005), pela população em geral ou por usuários de serviços públicos a partir de uma organização ou por meio de conselhos, plebiscitos e espaços de diálogo como, por exemplo, com o orçamento participativo.

De acordo com o Portal do Observatório Social do Brasil, como gestor da rede, este assume um importante meio de auxiliar as cidades que tiverem a disposição de implantar o processo de monitoramento dos gastos públicos a partir do desenvolvimento de uma metodologia que sintetiza e orienta para o trabalho local de acordo com os padrões das ações desenvolvidas pelos observatórios sociais.

Os observatórios podem gerar efeitos amplos em relação à cidadania e à democracia de uma cidade ou de um país embora, segundo Abrucio e Loureiro (2005), não tenham poder de exercer sanção direta sobre os governantes, e sim de ser mobilizador e influenciador de outros mecanismos como os controles: judicial, parlamentar ou administrativo.

É importante reforçar que, quanto às diferentes formações dos voluntários que estão atuando em diferentes regiões brasileiras, temos profissionais liberais relacionados à contabilidade, bancários, professores universitários, funcionários públicos aposentados, sindicalistas e aposentados.

Nesse contexto, o número 3 traz como título "Social Observatory as a new space for civil society and government relationships in Belém, Pará State, brazilian Amazon", da autoria de Jones Nogueira Barros, Mario Vasconcellos Sobrinho, Ana Maria de Albuquerque Vasconcellos e Airton Cardoso Cançado, que analisam o Observatório Social (OS) como uma nova arena para o diálogo entre a sociedade, o mercado e o governo e sua incidência na política pública.

Outro artigo que apresenta uma relação com o tema discutido é "Contribuições de três organizações para a comercialização da agricultura familiar no PNAE, no território sul litorâneo do Espírito Santo", de autoria de Suely Ferreira da Cruz e Thiago Rodrigo de Paula Assis. Os autores analisam as contribuições, vantagens e desvantagens de três organizações da agricultura familiar para a execução do PNAE, no território Sul Litorâneo do Espírito Santo (grupo informal, associação e cooperativa).

Neste número, encontramos uma diversidade de interfaces temáticas com o caráter interdisciplinar que permeia a revista, ao discutir a inserção de piscicultores de tilápia em redes 
sociais, como também sobre o desenvolvimento local, a questão do emprego turístico em Mato Grosso do Sul, a análise do espaço urbano da cidade de Viçosa, MG e os estilos de lideranças predominantes em uma indústria madeireira no Meio-Oeste Catarinense.

Com relação à saúde, há um estudo realizado no bairro São Francisco, região urbana de Pitangui, Minas Gerais, com o propósito de investigar o conhecimento popular na utilização de plantas medicinais; outro artigo interessante versa sobre a avaliação da qualidade da terapia nutricional em uma unidade de terapia intensiva para adultos em um hospital universitário brasileiro, assim como políticas de saúde, especialmente através da Política Nacional de Saúde Integral LGBT.

Outro artigo que chama a atenção neste número, comenta a relação entre o sistema de vida de uma Comunidade Indígena Terena e alguns temas relacionados ao Desenvolvimento, estruturado ao redor de uma narrativa de base a partir do discurso de um líder indígena.

Interações, Revista Internacional de Desenvolvimento Local, chega ao seu volume 20, terceiro número do ano de 2019, com muitas motivações e agradecimentos. Aos pesquisadores avaliadores, seja da Comissão Editorial como também dos avaliadores ad hoc, os nossos sinceros agradecimentos pelos esforços e dedicação a este número. Crescemos gradativamente no número de colaboradores assim como na submissão de artigos à Interações, demonstrando de forma inequívoca o caráter interdisciplinar proposto pela Revista.

A diversidade temática das abordagens nos artigos tem uma relação direta com o Desenvolvimento Local e com as Linhas de Pesquisa do nosso Programa de Mestrado e Doutorado. Neste ano de 2019, passamos a privilegiar a publicação de dossiês temáticos, e o primeiro tendo por tema a "Rota Bioceânica" já se encontra à disposição dos nossos leitores com 19 artigos sobre a temática.

O nosso agradecimento especial vai também para a nossa equipe da Editora, que não tem medido esforços para a publicação dos números da Interações.

\author{
Arlinda Cantero Dorsa ${ }^{1}$ \\ Editora chefe da Interações
}

\title{
REFERÊNCIAS
}

OBSERVATÓRIO SOCIAL DO BRASIL. Disponível em: http://osbrasil.org.br/. Acesso em: 20 ago. 2019.

ABRUCIO, F. L.; LOUREIRO, M. R. Finanças públicas, democracia e accountability. In: BIDERMAN, C.; ARVATE, P. R. (Org.). Economia do Setor Público no Brasil. Rio de Janeiro: Campus, 2005.

\section{Sobre a autora:}

Arlinda Cantero Dorsa - Doutora em Língua Portuguesa pela Pontifícia Universidade Católica de São Paulo (PUC-SP). Professora na Universidade Católica Dom Bosco (UCDB). E-mail: acdorsa@ucdb.br, Orcid: http://orcid.org/0000-0002-1120-0273

\footnotetext{
${ }^{1}$ Universidade Católica Dom Bosco (UCDB), Campo Grande, Mato Grosso do Sul, Brasil.
} 